\title{
As agências internacionais e as políticas de saúde nos anos 90: um panorama geral da oferta de idéias
}

\author{
The international agencies and the health policy
} in the 1990's: a general view of the offer of ideas

Ruben Araújo de Mattos 1

1 Instituto de Medicina Social da Universidade do Estado do Rio de Janeiro. Rua São Francisco Xavier, 524/70 andar, bloco D, Maracanã, 20550-013, Rio de Janeiro RJ. rubenm@uol.com.br

\begin{abstract}
This paper presents a discussion about the international agencies' contributions to health policy during the 1990's. The international agencies are considered members of an international development assistance community, which includes the United Nations agencies and funds, the World Bank and the regional development banks, and the national agencies for international co-operation. The international agencies seem to be more and more engaged in offering ideas of the more adequate policies to the so-called developing countries. The narrative presented here points out the dimension of the phenomenon of the offer of ideas yet not much discussed in literature: that these ideas can be understood within the dynamics of competition and co-operation in the international development assistance community. With the publication of Investing in Health, in 1993, the World Bank turned to be one of the most important agencies in the discussion of international health issues. But by the end of the decade, the World Health Organization tried to become an important agency in giving advice to govermments about the national health systems' reforms. The article discusses the more important issues presented in the documents of both agencies.

Key words International agencies, World Bank, World Health Organization, Health policy
\end{abstract}

Resumo Este texto apresenta um panorama da atuação de algumas agências internacionais, no que se refere às politicas de saúde da década de 1990. Essas agências integram a comunidade internacional de ajuda ao desenvolvimento, constituída pelas agências e fundos das Nações Unidas, pelo Banco Mundial, pelos bancos regionais de desenvolvimento e pelas agências governamentais de cooperação internacional. O artigo destaca que as agências internacionais têm-se dedicado cada vez mais à oferta de idéias sobre quais seriam as politicas mais adequadas aos países em desenvolvimento. O texto defende a tese de que a oferta de idéias pode ser melhor compreendida no contexto da dinâmica de competição/cooperação entre os membros daquela comunidade. Com a publicação do documento "Investindo em saúde" (1993), o Banco Mundial alcançou um lugar proeminente no cenário do debate internacional acerca das politicas de saúde. Desde os últimos anos da década, contudo, a OMS vem tentando obter um lugar mais relevante quanto ao oferecimento de conselhos para os governos dos países-membros, sobre as reformas em seus sistemas nacionais de saúde. São apresentados os principais eixos das propostas feitas ao longo da década pelo Banco Mundial e pela OMS, para o conjunto dos países.

Palavras-chave Agências internacionais, Banco Mundial, Organização Mundial de Saúde, Políticas de saúde 
Este pequeno texto procura oferecer um panorama geral da atuação das agências internacionais no processo de formulação de políticas de saúde nos anos noventa. Entre as diversas formas de atuação, destacamos a oferta de idéias sobre quais seriam as políticas de saúde mais adequadas para os países ditos em desenvolvimento. Tal destaque justifica-se por ser esse um traço marcante, quiçá predominante, da atuação daquelas agências nos anos 90. Embora a oferta de idéias por parte das agências internacionais seja bastante antiga, no final dos anos 80 ela adquiriu novas características, que se constituíram num novo padrão na década de 1990.

Até os anos 70, uma grande parte das sugestões de políticas emanadas das agências internacionais e fóruns internacionais de discussão surgiam de amplos debates entre representantes dos diversos países. A cooperação técnica e o diálogo político eram as ferramentas fundamentais postas em ação para granjear a adesão dos governos àquelas propostas de políticas. Em contraste, os anos 80, no contexto das propostas de ajuste estrutural, trouxeram à tona um outro modo de desenvolver e difundir sugestões de políticas, agora especificamente voltadas para os países em desenvolvimento. As propostas de política passaram a ser elaboradas num âmbito restrito a algumas agências internacionais e aos principais governos do mundo, disseminando-se com a ajuda de dispositivos de indução (como os empréstimos condicionados à adoção de certas políticas econômicas). Nos anos 90, há uma retomada do diálogo político em duas dimensões: o diálogo entre as próprias agências internacionais e o diálogo das agências com cada governo. Mas há a persistência de uma assimetria que vinha já da década de 1980: as sugestões de quais seriam as políticas mais adequadas aos países em desenvolvimento são elaboradas no âmbito das agências internacionais. O diálogo político com cada governo, mesmo que adotando em menor grau as condicionalidades, visa obter a sua adesão às sugestões já elaboradas. A emergência desse novo padrão de atuação foi simultânea à crescente proeminência do Banco Mundial no que diz respeito ao debate sobre as políticas de saúde no cenário internacional.

Este artigo tem um caráter exploratório, derivado de uma constatação: embora ninguém hoje negue a importância das agências internacionais no processo de elaboração e implementação de políticas de saúde no âmbito nacional, ainda são relativamente escassos os estudos que se dedicam ao exame específico de sua atuação. Nesse contexto, seria imprudente pretender traçar um quadro abrangente e exaustivo daquela atuação. Assim, o panorama geral que aqui se oferece é tão somente um esboço, que, esperamos, suscite novas hipóteses para trabalhos posteriores, e contribua para ampliar o leque de leituras que dispomos sobre a contribuição de agências como o Banco Mundial e a Organização Mundial de Saúde.

O texto está formalmente organizado em seis tópicos. No primeiro, ainda introdutório ao trabalho, explicitamos a noção de agência internacional que será utilizada aqui, destacando sua inserção na ordem mundial e, de modo mais particular, no que chamamos de comunidade de ajuda internacional. No segundo, buscamos caracterizar o padrão de oferta de idéias como uma das atividades mais importantes (senão a mais importante) das agências internacionais, num processo que foi acompanhado pela maior presença do Banco Mundial no debate das políticas públicas em geral. O terceiro tópico volta-se para a saúde e traça, a partir de um retrospecto ligeiro, as inflexões que vêm ocorrendo na atuação e nas posições relativas de algumas agências no âmbito da comunidade internacional que elas integram. Examinamos, no quarto tópico, o processo através do qual o banco mundial adquiriu nos anos 90 uma posição proeminente no debate sobre as políticas de saúde, identificando, já no quinto tópico, as suas principais sugestões. Dedicamos o sexto tópico ao exame, ainda que sucinto, do engajamento mais recente da Organização Mundial de Saúde na oferta de idéias sobre as reformas dos sistemas de saúde. O recorte neste artigo privilegia, portanto, apenas algumas das novas propostas de política de saúde, exatamente aquelas que nos parecem ter conferido características peculiares ao debate sobre as políticas de saúde na década de 1990, tanto as originárias do Banco Mundial como as mais recentes proposições da Organização Mundial de Saúde.

\section{Agências internacionais, ordem mundial e comunidade de ajuda internacional}

Há uma série de organizações cuja atuação ultrapassa as fronteiras nacionais - firmas (agentes econômicos privados), organizações governamentais, organizações não-governamentais, organizações clandestinas (como as ligadas ao 
tráfico de drogas) etc. Contudo, não é o critério da abrangência transnacional da atuação de uma agência que a qualifica como uma agência internacional, pelo menos no modo como se utiliza essa expressão neste trabalho. Aqui, definimos agências internacionais baseados num outro critério: a participação de vários governos nacionais (pelo menos três) na constituição e na sustentação financeira e política de uma organização (Walt, 1996). Os governos que constituem e sustentam as agências internacionais são denominados de países-membros.

Toda agência internacional é constituída através de um acordo entre vários governos nacionais, em que se estabelece sua missão, os dispositivos de seu próprio governo, os dispositivos pelos quais a agência obterá os recursos financeiros e as regras básicas de sua atuação. É claro que todas as regras básicas que regem a atuação de uma agência internacional podem ser reinterpretadas e repactuadas em qualquer tempo pelos países-membros. Sendo firmados politicamente entre governos com poderes políticos, militares e econômicos distintos, e com interesses diferentes, tais pactos expressam sempre as relações de poder entre os diversos governos numa conjuntura internacional dada e, portanto, as estratégias de disputas pela hegemonia. Hegemonia que se expressa na capacidade de um governo de impor aos demais as regras e as medidas que melhor atendem aos seus interesses particulares, como se elas também atendessem aos interesses de todos os demais.

Em outros termos, as agências internacionais integram os dispositivos de reprodução da ordem mundial, incluindo aí a sempre mais restrita possibilidade de sua transformação. Isso não significa que tais agências sejam sempre os principais dispositivos de sustentação de uma certa ordem mundial, nem tampouco que sua atuação possa ser interpretada como sendo o simples reflexo dos interesses dos governos nacionais hegemônicos numa certa conjuntura.

Talvez um dos traços marcantes da ordem mundial que se instituiu após a Segunda Guerra seja a criação de um amplo conjunto de organismos internacionais, dentre os quais destacam-se as instituições de Bretton Woods e aquelas ligadas às Nações Unidas (Arrighi, 1996).

A famosa conferência de Bretton Woods realizou-se por proposta do governo norte-americano, ainda durante a Segunda Guerra, e teve como principal objetivo traçar os contornos da nova ordem econômica que deveria ser instituída após a vitória dos aliados. Dela resultou a proposta da criação de duas agências internacionais - o Fundo Monetário Internacional (FMI) e o Banco Internacional para a Reconstrução e o Desenvolvimento (BIRD, primeira organização do chamado Banco Mundial). Ao mesmo tempo, era estabelecido um novo padrão monetário internacional, centrado no dólar com paridade fixa com o ouro (Mattos, 2000).

O BIRD foi concebido para oferecer empréstimos aos países-membros, financiando projetos para os quais não fosse possível obter recursos nos mercados financeiros em condições razoáveis. Para tal, o BIRD emitiria títulos em bônus, captando recursos nos mercados financeiros. Esses papéis do banco até hoje são considerados bastante seguros, pois têm como lastro as cotas de contribuição dos países-membros.

Também por proposição do governo norteamericano, logo após o fim da Segunda Guerra foi criada a Organização das Nações Unidas (ONU), um conjunto de seis organismos, voltados fundamentalmente para a sustentação da segurança e da paz mundial. ${ }^{1}$ Em torno da ONU surgiram várias agências internacionais especializadas, como a Organização Mundial de Saúde (OMS), e foram criados alguns fundos e alguns programas das Nações Unidas como o Fundo das Nações Unidas para a Infância (UNICEF).

A OMS é a agência especializada das Nações Unidas para a saúde. ${ }^{2}$ Concebida para oferecer cooperação técnica entre os países-membros, ela se engaja em um grande número de iniciativas de enfrentamento de problemas de saúde, bem como de iniciativas voltadas ao aprimoramento dos sistemas de saúde. Para tal, a OMS conta com recursos de duas fontes: os recursos orçamentários das Nações Unidas e os extraorçamentários, oriundos de doações voluntárias de países-membros a projetos específicos.

Portanto, a arquitetura institucional desses dois sistemas de organizações internacionais as Nações Unidas e as instituições de Bretton Woods - foi desenhada pelo governo americano como parte de seu projeto político de hegemonia mundial. O que não significa que essas agências tenham tido importância na sustentação dessa hegemonia, nem que suas contribuições para tal projeto hegemônico tenham sempre tido a mesma significação. Por exemplo, há analistas, como Arrighi, que ressaltam que o Banco Mundial e o FMI tiveram inicialmente um papel muito secundário na afirmação da hegemonia norte-americana. Para esse autor, tais agências só adquiriram maior importância 
internacional na década de 1970, num momento em que as elites dirigentes norte-americanas manifestavam desprezo pelo governo do mundo (Arrighi, 1996). Independentemente de acolhermos os argumentos de Arrighi, eles servem para colocar em xeque algumas interpretações reducionistas, que querem ver na atuação do Banco Mundial e do FMI apenas o reflexo dos interesses norte-americanos.

Das considerações anteriores deriva-se uma consideração metodológica importante. Se por um lado, torna-se difícil compreender a atuação das agências internacionais sem ter como pano de fundo uma leitura das estratégias dos diversos governos que de algum modo disputam a hegemonia mundial, por outro, tampouco se pode deixar de considerar a dinâmica das relações que as agências internacionais estabelecem entre si e com os governos que ao fim e ao cabo garantem a sustentação política e econômica dessas agências. Em outros termos, os acordos que permitiram o nascimento desse conjunto de agências internacionais no pósguerra, quando vistos em seu conjunto, estruturam uma série de relações entre países-membros e cada uma das agências, tanto no que diz respeito ao modo de governo como ao modo de sustentação econômica das mesmas. Analogamente, o conjunto de acordos delineia uma certa divisão de trabalho entre as agências internacionais, divisão essa que é sempre reinterpretada e renegociada a cada conjuntura, tanto em função das mudanças nas estratégias dos países-membros em suas disputas pela hegemonia, como (porque não levantar essa possibilidade) em função das estratégias de dirigentes dessas agências internacionais.

As instituições de Bretton Woods e as agências e fundos do sistema das Nações Unidas têm estruturas de governo distintas em pelo menos um aspecto fundamental: o peso dos diversos países-membros nos processos decisórios. Em instituições como a OMS e o UNICEF, todos os países-membros têm o mesmo poder de voto nas instâncias de governo do qual participem; nas de Bretton Woods, o poder de voto de um país é proporcional à participação do mesmo na composição dos recursos financeiros da agência. Obviamente, isso cria mais oportunidades para que os países mais desenvolvidos possam influenciar os rumos, tanto do Banco Mundial como do FMI. Mas não se deve desprezar o poder de influência desses mesmos países sobre as demais organizações internacionais. A maioria das agências ligadas às Nações
Unidas utiliza recursos extra-orçamentários provenientes de doações voluntárias dos países-membros a projetos específicos. E a maioria desses recursos provém dos países desenvolvidos, que desse modo influenciam diretamente as iniciativas dessas agências internacionais.

Se o período do pós-guerra imediato foi o momento de configuração de uma nova arquitetura da ordem mundial, que incluía as agências que mencionamos, a década de 1960 assistiu a uma remodelagem significativa desse arranjo, quer pela criação de novas agências internacionais, quer pelo estabelecimento, nos países desenvolvidos, de agências governamentais voltadas à cooperação internacional.

De um lado, ao longo da década de 1960, governos de países desenvolvidos criaram (ou reformularam radicalmente) agências voltadas para a cooperação internacional. Estas, articuladas com a política externa de seus próprios governos, buscavam defender seus interesses específicos junto a outros países, através de empréstimos ou doações de recursos às nações ditas em desenvolvimento. De fato, até a década de 1990, o volume de recursos transferidos anualmente para os países em desenvolvimento por estas agências nacionais de cooperação internacional (através de doações ou de empréstimos facilitados) cresceu continuamente.

Também com grande apoio (e pressão) do governo norte-americano, no início dos anos 60 foi criada, no âmbito do Banco Mundial (BM), a Associação Internacional de Desenvolvimento (AID). A AID oferece empréstimos de longo prazo sem juros (portanto, em condições mais facilitadas do que o BIRD) a alguns países-membros. ${ }^{3}$ Ao contrário do BIRD, que capta os recursos no mercado financeiro internacional, a AID obtém seus recursos a partir de um fundo constituído pelos países-membros. Apesar de ser contabilmente outra agência, a AID partilha com o BIRD o mesmo corpo técnico, constituindo-se parte do chamado Banco Mundial.

Também na década de 1960, no âmbito das Nações Unidas, surgiram inovações. Atendendo a uma crescente pressão dos países em desenvolvimento, que buscavam novas formas de obter recursos externos para seus projetos de desenvolvimento, foi criado o Programa das Nações Unidas para o Desenvolvimento (PNUD). A preocupação com a ajuda externa ao desenvolvimento de fato tornou-se central na agenda das instituições do sistema das Nações Unidas, a ponto de se chamar o período de a "década do desenvolvimento". 
A busca de novas modalidades de financiamento externo para o desenvolvimento já havia, no final dos anos 50, levado à criação do Banco Interamericano de Desenvolvimento (BID). Outros bancos regionais de desenvolvimento surgiram ao longo da década de 1960. Ao final da década, o conjunto de organismos internacionais e nacionais (sempre dos países desenvolvidos) envolvidos na mediação da transferência de recursos rumo aos países desenvolvidos havia crescido enormemente. Esses organismos integravam uma rede complexa e se apresentavam como uma comunidade de ajuda internacional ao desenvolvimento. No seu interior havia (e há) uma dinâmica de competição/cooperação, isto é, um contínuo processo de negociação sobre uma certa divisão de trabalho na ajuda internacional. Nessa nova arquitetura da ordem mundial, caracterizada pela emergência dessa comunidade internacional de ajuda ao desenvolvimento, intensificam-se as relações entre agências internacionais (quer sejam elas de cooperação técnica, quer sejam instituições financeiras) e agências governamentais de ajuda internacional. Em conseqüência, não podemos analisar a contribuição das agências internacionais nas políticas de saúde sem vislumbrar as mudanças na dinâmica dessa nova comunidade internacional.

Uma das principais marcas dos anos 90 é a crise dessa comunidade do desenvolvimento. Após uma década de hegemonia das idéias neoliberais, o tema do desenvolvimento deixou de ser central, pelo menos para as elites dirigentes dos países desenvolvidos, que ao fim e ao cabo dão a sustentação política e financeira àquela comunidade internacional. $\mathrm{O}$ fim da Guerra Fria e a elevação do fluxo de capitais privados rumo aos países em desenvolvimento (ou melhor, rumo aos países em desenvolvimento, cujos governos faziam o "dever de casa", implantando uma austera disciplina macroeconômica, reduzindo gastos públicos e realizando programas de privatizações) colocaram em xeque a necessidade de uma ajuda internacional ao desenvolvimento. Por outro lado, a política de contenção dos gastos públicos dos governos dos países desenvolvidos passou a impor aos setores menos importantes (como a cooperação internacional) cortes orçamentários significativos. Assim, desde 1993, os recursos mobilizados pelas agências nacionais de cooperação internacional vêm caindo. Pelo fato de parte desses recursos governamentais sustentar algumas agências internacionais, como as agências especializadas e os fundos das $\mathrm{Na}$ ções Unidas, a crise atinge amplamente a comunidade do desenvolvimento.

Como parte da resposta à crise, agências nacionais e internacionais empreenderam nos anos 90 um esforço de construir uma nova razão para sua existência, que não a simples idéia de ajuda ao desenvolvimento. A redução da pobreza surge como novo mote, visto como tendo o potencial de reverter ou atenuar a queda dos recursos mediados pela comunidade internacional. Na defesa dessa causa, surgem tanto argumentos que apelam para o compromisso moral (e humanitário) de atenuar a pobreza no mundo, como que evocam as ameaças que o crescimento da pobreza periférica oferece para o próprio desenvolvimento e ordem nos países desenvolvidos. É em torno da meta de eliminar a pobreza até 2015 que se agrega a maioria das agências internacionais (OECD/DAC, 1996).

A estratégia do Banco Mundial nos anos 90 merece ser destacada. Primeiramente, o Banco, que esteve intimamente associado ao FMI nos anos 80 na difusão das propostas de ajustes estruturais, começou a demarcar as diferenças entre sua missão e a de seu irmão gêmeo. ${ }^{4} \mathrm{Em}$ segundo lugar, o Banco buscou ativamente se aproximar das organizações não-governamentais, que vinham intensificando sua mobilização crítica ao papel das instituições de Bretton Woods na sustentação da ordem mundial. Em terceiro lugar, o Banco aderiu ao novo mote do combate à pobreza, fazendo coro ao grande número de agências internacionais. Ele cunhou seu novo slogan - "nosso sonho é um mundo sem pobreza" -, e adotou a prática discursiva de justificar todas as suas iniciativas (inclusive suas recomendações de austeridade fiscal) como se as mesmas tivessem algum impacto positivo sobre a pobreza. Por fim, o banco buscou intensificar o diálogo com as demais agências internacionais e órgãos de cooperação internacional, com vistas a produzir consensos sobre o que deve e o que não deve ser apoiado por essa comunidade internacional. É nesse contexto que a oferta de idéias assumiu grande destaque.

\section{A década da oferta de idéias}

No discurso que proferiu, em 1997, diante da Assembléia dos Governadores do Banco Mundial (que inclui as maiores autoridades econômicas de todos os países-membros), o presidente do Banco Mundial dizia: Mas, como co- 
munidade de desenvolvimento, o que podemos fazer é, certamente, ajudar os países mediante a provisão de financiamento, mas, ainda mais importante que isso, de conhecimento e lições sobre os desafios e a maneira de enfrentá-los (Wolfensohn, 1997).

Note-se que, para o Wolfensohn, a missão do banco e de toda a comunidade de ajuda ao desenvolvimento consistiria não só em oferecer recursos financeiros, mas também, senão principalmente, oferecer idéias. De fato, na medida que os governos dos países desenvolvidos reduziam o volume de recursos que colocavam à disposição para a ajuda externa ao desenvolvimento, cresceu a importância da oferta de idéias acerca das políticas que deveriam ser adotadas pelos países em desenvolvimento. $\mathrm{Ou}$, pelo menos, acerca das políticas que deveriam ser apoiadas pela chamada comunidade do desenvolvimento, cada vez mais empenhada em combater a pobreza.

A importância dada pelo Banco Mundial e por muitos doadores e agências internacionais à oferta de idéias apoiou-se em um argumento que atribui a eficácia da ajuda aos países desenvolvidos mais ao aconselhamento político do que aos empréstimos ou doações. Encontramos esse argumento, por exemplo, em um trecho do documento do Banco Mundial acerca da estratégia para o setor de saúde, nutrição e população: Uma avaliação do impacto das atividades do Banco mostra que a maior parte da ajuda externa ao setor de saúde, nutrição e população simplesmente substitui gastos governamentais. A origem real da eficácia no setor são, portanto, as reformas resultantes do aconselhamento político que acompanha os empréstimos, $e$ não dos empréstimos em si (World Bank, 1997).5

Talvez em virtude dessa visão, algumas agências, como o Banco Mundial, têm intensificado suas atividades de pesquisa e discussão de temas ligados ao desenvolvimento e/ou à redução da pobreza. O preparo e a divulgação de documentos são uma das formas mais visíveis dessa oferta de idéias. Há, em linhas gerais, dois tipos de documentos: os que abordam um tema em geral, sem menção específica a um país; e os que se voltam especificamente a um determinado país. O segundo tipo de publicação volta-se predominantemente para o governo em questão, inscrevendo-se no diálogo político da agência com o referido país. Já o primeiro tem dois públicos-alvo distintos (ou, para usar um termo muito caro à retórica, dois auditórios distintos): os governos dos países em desenvol- vimento em geral e os membros da comunidade internacional de ajuda ao desenvolvimento.

No que diz respeito ao diálogo entre diversas agências da comunidade internacional, podemos dizer que ele integra o diálogo político que visa estabelecer consensos no interior dessa comunidade, acerca de quais iniciativas, projetos e políticos devem ser apoiados.

O consenso, nessa comunidade, sobre algumas propostas de política que os governos dos países em desenvolvimento deveriam adotar, abre uma série de perspectivas. Ele permite regular diretamente, pela coordenação entre diversas agências, os destinos do fluxo de recursos intermediados por essa comunidade; permite ainda oferecer aos mercados privados avaliações sobre os desempenhos dos governos que se candidatam a captar recursos privados. Dessa forma, as agências asseguram sua participação na sustentação da ordem mundial. Além disso, o consenso parece oferecer um patamar mais sólido para as decisões de alocação de recursos que são confiados à comunidade internacional, pois indicaria o zelo pelo bom uso destes, essencial para reforçar a crença sobre a importância dessa ajuda junto aos governos que dão sustentação a esta comunidade. Mas o consenso serve também para afirmar a proeminência da organização que elaborou as propostas em torno das quais se deu o consenso. Desse modo, ele se inscreve na dinâmica de competição e cooperação que existe entre doadores e agências internacionais.

As diversas agências internacionais, contudo, engajaram-se diferentemente na oferta de idéias. Se é fato que praticamente todas elaboram documentos anuais que abordam aspectos do desenvolvimento, e a maioria dispõe de sistemas de monitoração dos aspectos de desenvolvimento mais caros à sua forma de atuação específica, ${ }^{6}$ as condições para a realização das tarefas de pesquisa e análise dos temas, bem como de produção desses documentos, são bastante distintas.

O Banco Mundial parece ser uma das agências com maior capacidade de responder ao desafio de ofertar idéias aos governos e aos demais parceiros da comunidade internacional de ajuda ao desenvolvimento. O Banco parece tirar vantagem de sua atuação em diversos setores, de sua experiência mundial e de uma estrutura interna que permite produzir sugestões de políticas e apresentá-las como se as mesmas tivessem sido extraídas de sua abrangente experiência. Ademais, o Banco pode mobilizar gran- 
des quantidades de recursos, diretamente ou através das parcerias que estabelece (World Bank, 1997).

De fato, ao longo dos anos 80 e, sobretudo, dos anos 90, o Banco passou a oferecer idéias sobre um amplo elenco de temas e políticas, tornando-se um interlocutor privilegiado no interior da comunidade internacional de ajuda ao desenvolvimento.

Já se disse que o Banco geralmente ingressa num debate de um setor ou de um tema formulando um ataque às principais premissas que vinham orientando a discussão até então. Isso deslocaria o eixo do debate, colocando o Banco e seus argumentos no centro dos embates (Wade, 1996). O banco ficaria assim em condições privilegiadas para catalisar a produção de um consenso. Independentemente da pertinência dessa descrição geral, ela parece ter-se aplicado ao que diz respeito à saúde. Com efeito, o banco adquiriu, ao longo da década de 1990, posição de destaque nos debates sobre as políticas de saúde no cenário internacional.

\section{A proeminência do Banco Mundial nos debates acerca das políticas de saúde}

Para ressaltar as mudanças que ocorreram na posição relativa das agências internacionais nos anos 90 e destacar a proeminência que o Banco Mundial adquiriu, pode ser oportuno recuar um pouco no tempo, ainda que rapidamente.

A famosa Conferência de Alma-Ata, realizada em 1978, foi sem dúvida um marco nos debates internacionais acerca das políticas de saúde. A conferência se debruçou sobre um relatório conjunto dos diretores dos dois organismos: a OMS e o UNICEF. Para muitos, as conclusões de Alma-Ata significaram um avanço na construção de um consenso, entre a maioria dos governos do mundo, quanto à importância das estratégias de expansão dos cuidados primários de saúde, a serem conduzidas com ampla participação do Estado. De fato, os ideais defendidos por Alma-Ata parecem ter orientado a posição da OMS e de suas agências regionais até bem recentemente. Mas ela também pode ser vista como o último suspiro de um padrão de cooperação internacional. Talvez tenha sido a última vez em que a voz dos países em desenvolvimento foi levada a sério num fórum internacional.

Com efeito, os anos 80 logo trouxeram muitas transformações no cenário mundial. Embo- ra a década de 1970 tenha se iniciado sob o signo da crise monetária internacional, que implicou inclusive a ruptura unilateral por parte do governo norte-americano do padrão monetário instituído em Bretton Woods, o impacto sobre a ordem mundial das inflexões da política econômica norte-americana na virada dos anos 80 foi marcante (Fiori, 1997; Teixeira, 1994). A decisão política de valorizar o dólar fez com que os Estados Unidos passasse a atrair os recursos financeiros dos mercados internacionais, elevando o custo do dinheiro e agravando dramaticamente as dívidas dos países em desenvolvimento. Por sua vez, a difusão das idéias neoliberais, com epicentro nos governos dos Estados Unidos e da Inglaterra, reduziu a disposição de muitos governos para empreender iniciativas governamentais, tanto na esfera econômica como na social. O tema dos ajustes estruturais, isto é, as reformas supostamente indispensáveis para que os países em desenvolvimento se ajustassem à nova dinâmica da economia mundial, tornou-se o centro do debate internacional sobre as políticas. Os anos 80 foram os anos do ajuste.

O FMI e o Banco Mundial se engajaram no esforço de difundir as propostas de ajuste, criando novas modalidades de empréstimos, nas quais recursos não vinculados a projetos eram repassados aos governos, para alívio da delicada situação de suas balanças de pagamento, mediante o compromisso desses governos de adotarem um conjunto de medidas econômicas recomendadas.

Nesse contexto, e sob a égide de governos conservadores, as agências de cooperação do sistema das Nações Unidas perderam prestígio frente às instituições de Bretton Woods. Afinal, estas últimas pareciam estar mais capacitadas a participar do esforço no sentido de induzir os países em desenvolvimento a adotar as políticas supostamente mais adequadas aos novos tempos. Evidentemente, não era esse o espírito de Alma-Ata.

Por sua vez, logo no início dos anos 80, o UNICEF produziu uma pequena, mas significativa ruptura com o consenso estabelecido em Alma-Ata. Seu novo diretor, James Grant, convencido de que o custo da expansão dos cuidados primários de saúde numa perspectiva universal não poderia ser suportado por muitos países, passa a defender o uso de um pacote mais seletivo de intervenções altamente efetivas em termos de custo (UNICEF, 1996). Grant propôs à comunidade do desenvolvimento um 
esforço para financiar a realização desse pacote mínimo, cujos impactos sobre a saúde das crianças seriam uma verdadeira revolução. Em torno da idéia aglutinaram-se várias agências, como a própria OMS, o PNUD, o Banco Mundial e a Fundação Rockefeller (uma organização privada, portanto, não-governamental, com grande tradição no financiamento de algumas ações de saúde em vários países). A iniciativa de oferecer propostas que permitiram aglutinar recursos de várias fontes e empreender um esforço internacional que parece ter tido impacto na mortalidade infantil colocou o UNICEF numa posição de destaque na década, no que se refere à saúde.

Ao mesmo tempo, o Banco Mundial passava a financiar projetos no setor saúde. O primeiro empréstimo do Banco especificamente dedicado ao setor ocorreu em 1981. Mas rapidamente o banco elevou o volume de recursos destinados ao setor, de modo que ao final da década era um dos maiores provedores de recursos externos para a saúde (World Bank, 1987).

Aproximadamente em meados da década, o banco decidiu ingressar no debate acerca das políticas de saúde, e iniciou o desenvolvimento de pesquisas, com vistas a produzir um documento acerca das políticas de financiamento para o setor (Mattos, 2000). O documento, intitulado "Financing health services in developing countries: an agenda for reform" (Financiando serviços de saúde: uma agenda para reforma), apresentava uma proposta de redução da responsabilidade dos governos no financiamento dos serviços de saúde. Embora as idéias que circulavam amplamente no interior do banco naquela ocasião colocassem em dúvida qualquer forma de participação governamental em qualquer setor da economia, o documento partia de um ponto de vista mais ameno, e mais próximo da posição das demais agências com as quais pretendia dialogar. $\mathrm{O}$ argumento apresentado reconhecia que a participação dos governos na saúde era responsável pela grande melhoria nas condições de saúde que se observava desde a Segunda Guerra, mas advertia que as condições que possibilitaram tal êxito no passado não continuariam a existir no futuro próximo. Tratava-se de uma posição pessimista.

Três argumentos foram apresentados pelos autores do documento para esse "pessimismo". Primeiramente, afirmava-se que grande parte da melhora obtida tinha decorrido da adoção de tecnologias cuja eficácia não exigia mudanças comportamentais, o que não era mais o ca- so. A isso se somava a tese de que muitos poucos países haviam logrado levar os cuidados básicos de saúde às populações mais pobres do interior, passo consensualmente necessário para a continuidade dos ganhos na saúde. Em segundo lugar, defendia-se que a transição demográfica elevava a importância dos problemas relativos ao adulto, elevando a demanda por serviços de saúde assistenciais de baixa eficácia e alto custo, retirando assim recursos que de outra forma seriam destinados às ações básicas. E isso, em terceiro lugar, num contexto de restrição dos gastos públicos decorrente das supostas necessidades de ajustes macroeconômicos.

Essa linha de argumentação, contudo, encontrou forte resistência na comunidade internacional de desenvolvimento, especialmente no UNICEF. A crítica do UNICEF atacou o primeiro argumento, que, aliás, contrariava a experiência de redução da mortalidade infantil com técnicas como a terapia de reidratação oral, que, apesar de exigir mudanças comportamentais, parecia produzir resultados altamente positivos. O terceiro argumento também se tornou objeto de crítica, na medida que se desenvolveu na mesma época (final dos anos 80) uma densa crítica às propostas de ajuste que vinham sendo apresentadas. Crítica que, diga-se de passagem, contou com a ativa participação do UNICEF, que denunciou as conseqüências negativas de certas experiências de ajuste sobre as condições de vida das crianças. Baseado nessa avaliação, o UNICEF lançou no final dos anos 80 a proposta de um ajuste com face humana. Dos três argumentos utilizados inicialmente pelo banco, apenas o segundo ficou intocável. Tratava-se, contudo, de um argumento frágil, pois até então a reflexão sobre as conseqüências da transição demográfica sobre a saúde dos países em desenvolvimento era muito pouco desenvolvida.

No final dos anos 80 , o banco se via em condições de iniciar um conjunto de pesquisas orientadas a superar as resistências às suas principais propostas. Como os autores de " $\mathrm{Fi}$ nancing health services in developing countries: an agenda for reform" reconheciam: $O$ progresso em difundir idéias novas e desafiar as antigas tem sido lento porque as evidências em alguns tópicos são escassas. [...] O conhecimento sobre o financiamento de saúde chegou em um estágio no qual o retorno potencial de programas de pesquisa bem escolhidos é alto. Os temas centrais são claros, as hipóteses existem, o auditório 
a ser persuadido é grande e importante, e as técnicas para obter as informações necessárias são disponíveis (World Bank, 1987).

Nesse contexto, o Banco Mundial orientou suas investigações para o tema das conseqüências da transição demográfica, aproveitando-se de algumas vantagens comparativas: em sua estrutura organizacional, saúde e população estavam abrigadas sob o mesmo departamento; e o UNICEF não poderia dedicar especial atenção à saúde do adulto.

Dois trabalhos examinaram a saúde do adulto em dois países estratégicos, nos quais as transições demográficas estavam em curso, a saber, o Brasil e a China. Ao mesmo tempo, o banco empreendeu um estudo que proporcionou uma extensa revisão dos dados sobre a saúde do adulto nos países em desenvolvimento, municiando a discussão sobre as conseqüências da transição demográfica nesses países. Além disso, com a perspectiva de proporcionar subsídios para a definição de prioridades nos países em desenvolvimento, o banco promoveu uma ampla pesquisa sobre a eficácia, em termos de custo de várias intervenções na área da saúde.

Essas pesquisas trouxeram algumas mudanças nos eixos que orientavam a formulação das propostas. Em "Financing health services in developing countries: an agenda for reform", a redução da presença governamental se justificava, sobretudo, na distinção entre bens públicos e privados, reconhecidamente nebulosa. A idéia inicial, de adotar a disposição da população em pagar pelo serviço como um critério operacional de delimitação do que o governo deveria pagar, foi sendo abandonada. Em seu lugar, no início dos anos 90, surgiu a idéia de construir um critério de efetividade em termos de custo, que seria útil, principalmente, na construção de um pacote de intervenções a ser financiado pelos governos dos países em desenvolvimento. Essa foi a ênfase da pesquisa sobre as prioridades da saúde nesses países.

Em 1992, os resultados desses programas de pesquisa pareciam ser suficientemente promissores para que o banco decidisse dedicar um de seus relatórios sobre o desenvolvimento humano ao setor saúde. A elaboração de um relatório sobre o desenvolvimento mundial envolve a designação de uma equipe, que trabalha durante um ano na confecção do documento. No caso específico do relatório de 1993, mais conhecido por seu subtítulo "Investindo em saúde”, o esforço de investigação envolveu o preparo de doze trabalhos, especialmente encomendados para a ocasião, além de contar com o aporte de numerosas contribuições de outros técnicos do banco, e de tantas outras advindas dos diversos seminários e rodadas de discussão.

As investigações feitas especialmente para a produção do relatório "Investindo em saúde" caminharam na mesma direção das pesquisas que o banco vinha realizando desde o final dos anos 80. De um lado, foi desenvolvida uma medida capaz de servir a dois propósitos: medir a efetividade das intervenções disponíveis para enfrentar os principais problemas de saúde dos países em desenvolvimento, e desta forma integrar um critério de efetividade em termos de custo; e possibilitar um estudo de impacto da doença no mundo, que, aliás, terminou por banir o argumento pessimista, ao demonstrar que ainda havia muitos problemas de saúde que poderiam ser enfrentados com intervenções de baixo custo. Assim nasceu a medida dos anos de vida ajustados por incapacidade.

De outro lado, houve o desenvolvimento de uma proposta de pacote de cuidados, que teve por base os resultados da pesquisa sobre as prioridades de saúde, acompanhado de uma estimativa de seus custos em dois grupos de países: os de renda baixa e os de renda média. Um dos resultados desse estudo indicava a necessidade de ampliar os gastos governamentais em saúde em vários países de baixa renda e, em alguns casos, ampliar mesmo os gastos públicos de alguns países. Isso era contraditório com as recomendações de ajuste que o próprio Banco vinha fazendo nos anos oitenta.

Em conseqüência dessa trajetória de pesquisas, o Banco pode argumentar convincentemente, junto à comunidade internacional de ajuda ao desenvolvimento, que era desejável elevar a ajuda internacional voltada à saúde. $\mathrm{O}$ volume dos recursos da ajuda externa destinado à saúde vinha-se mantendo estagnado. E o banco, com o relatório de 1993, formulou convite para que a comunidade de doadores investisse mais em saúde. Por um lado, o texto mostrava que existiam intervenções altamente efetivas em termos de custo que mereceriam ser apoiadas. Por outro, o documento indicava que os países de baixa renda necessitariam obter mais recursos para essas atividades, o que ampliava a oportunidade e a necessidade de elevar a ajuda internacional. Por fim, em relação aos países de renda média, seria necessário apoiar a reforma e a reorientação dos sistemas de saúde, 
no sentido de assegurar a todos o acesso às intervenções custo-efetivas.

O Banco chegava a falar, por exemplo, que seria desejável uma elevação da ordem de dois bilhões de dólares na ajuda externa mediada pelas agências nacionais de cooperação destinada à saúde (Banco Mundial, 1993). Não deixa de ser curioso notar que o volume dessa ajuda, que se mantinha estagnado desde 1991, cresceu nos três anos subseqüentes à publicação do relatório do Banco, num ritmo de crescimento de cerca de um bilhão de dólares ao ano (Mattos, 2000).

O impacto da divulgação do relatório "Investindo em saúde" foi bastante grande. Pouco após sua publicação, a revista médica The Lancet lançou um editorial elogiando o documento do banco, no qual chegava a afirmar que o mesmo assinalava um deslocamento da liderança na saúde internacional da OMS para o Banco Mundial (Lancet, 1993).

Mas o documento também produziu impacto através das sugestões que oferecia sobre quais seriam as políticas mais adequadas para os países em desenvolvimento. O debate sobre as políticas de saúde da década foi marcado pela discussão dessas sugestões.

\section{As sugestões de políticas de saúde do "Investindo em saúde"}

"Investindo em saúde" é um bom exemplo da oferta de idéias pelo Banco Mundial. Nas palavras do próprio relatório: Mas para obter boas condições de saúde é essencial que haja boas políticas. Alguns países utilizaram plenamente os potenciais da medicina; outros quase não aproveitaram, apesar dos gastos volumosos. Desta múltipla experiência, o presente Relatório tira lições que ajudarão as autoridades a perceberem os enormes retornos em potencial dos investimentos que seus países fazem na área de saúde (Banco Mundial, 1993).

As principais lições oferecidas podem ser agrupadas em três categorias: as voltadas a criar um ambiente propício a que as famílias melhorem suas condições de saúde; as que pretendem tornar mais criteriosos os gastos públicos em saúde; e as que se voltam para a promoção da diversificação e da concorrência no setor (Banco Mundial, 1993).

No primeiro grupo inscrevem-se as sugestões de melhorar a escolaridade, sobretudo, das meninas (o que se justifica pela constatação de que a escolaridade das mulheres é um importante fator de queda da mortalidade infantil), e de promover os direitos e as condições da mulher. Também estão nesse grupo as medidas necessárias para assegurar o crescimento econômico, incluindo aqui as políticas de ajuste econômico. Os autores do documento, portanto, continuam insistindo na eventual necessidade de ajustes econômicos, inclusive com contenção dos gastos públicos. Mas defendem que os gastos públicos em saúde devem ser ativamente protegidos mesmo no contexto de ajuste econômico, desde que voltados para oferecer cuidados essenciais aos pobres. Esse argumento antecipa uma tese que se tornou central para o Banco no final da década: há que se proteger ativamente os pobres dos efeitos perversos das crises econômicas e das suas terapias.

O segundo grupo de sugestões volta-se para o redimensionamento da ação governamental e para o uso mais adequado dos gastos públicos. Para os autores, a intervenção governamental na saúde justifica-se por três conjuntos de argumentos distintos. Primeiramente, a redução ou o alívio da pobreza seria motivo suficiente para o engajamento dos governos na saúde. É que a doença deteriora mais a situação dos pobres. Garantir o acesso dos pobres a serviços de saúde eficazes e desse modo reduzir a deterioração seria um dos motivos principais para a intervenção governamental. Em segundo lugar, existiriam algumas ações que envolveriam grandes externalidades. Tipicamente, aqui estariam as atividades de saúde pública, cujos benefícios não poderiam ser apropriados privadamente. Em terceiro lugar, os governos deveriam atuar no sentido de corrigir as imperfeições dos mercados de seguros em saúde, regulando o setor prestador de serviços e incentivando a competição entre prestadores.

Os termos do "Investindo em saúde" são em geral mais brandos do que os do documento de 1987. Enquanto os autores de "Financing health services in developing countries: an agenda for reform", por exemplo, criticavam duramente os governos que viam a saúde como um direito e tentavam assegurar gratuitamente o acesso universal a todos os serviços (World Bank, 1987), no "Investindo em saúde" o discurso é mais moderado: Mas para se ter certeza de que os pobres tenham de fato acesso a serviços de saúde subsidiados, são talvez necessárias restrições, principalmente no tipo de atendimento que fica a cargo do setor público. Quando se oferece a todos, gratuitamente, todo tipo de atendi- 
mento, os serviços acabam sendo racionados por área geográfica ou segundo sua qualidade. Os programas universais talvez não cheguem até os pobres ou lhes melhorem a saúde. Mas podem granjear mais apoio politico do que granjeariam programas restritos a determinadas clientelas. [...] Para se determinar quem deve receber atendimento gratuito é preciso considerar a prevalência da pobreza e a capacidade do país para financiar o atendimento (Banco Mundial, 1993).

Há, portanto, uma crítica à posição de que cabe aos governos garantir o acesso universal gratuito aos serviços de saúde, mas que admite uma possibilidade de oferta bem mais abrangente de serviços. O pacote essencial, composto exclusivamente de intervenções altamente custo-efetivas, seria o mínimo que deveria ser financiado com recursos governamentais, cabendo a cada país avaliar a adequação de expandi-lo.

Por sua vez, as imperfeições do mercado de serviços médicos exigiriam uma atuação reguladora dos governos. O documento defende que as intervenções de saúde, que não são tão custo-efetivas como as do pacote de cuidados essenciais, deveriam ser financiadas pela iniciativa privada ou por alguma forma de seguro social. Com essa última expressão, o documento se refere às modalidades de seguro financiadas por "impostos destinados a determinados fins, como os esquemas de seguridade social e outros esquemas obrigatórios" (Banco Mundial, 1993). Note-se que o Banco parece estar mais preocupado com a utilização dos recursos provenientes dos impostos em geral do que com uma eventual participação governamental na gestão de recursos da seguridade, desde que captados por fontes específicas.

Outra questão relevante diz respeito à atuação governamental não no financiamento, mas na prestação de serviços. O tom aqui também é moderado, embora a posição seja firme: Não há teoria ou experiência que nos indique até que ponto o setor público deve prestar assistência médica diretamente (em vez de financiá-la) (Banco Mundial, 1993). Mesmo assim, o documento sugere que talvez caiba ao setor público oferecer aqueles serviços essenciais em áreas nas quais seriam necessários muitos subsídios para que o setor privado viesse a atuar com eficácia. Mesmo nesses casos, o documento concebe que, em alguns lugares, existe a alternativa de subsidiar organizações não-governamentais. Caberia ao governo, muito mais que assumir a prestação, incentivar a competição entre pro- vedores de serviços, inclusive entre provedores públicos e privados com ou sem fins lucrativos.

Em síntese, as questões apresentadas e as posições defendidas no documento Investindo em saúde pautaram o debate internacional acerca das políticas de saúde para os países em desenvolvimento, sobretudo as políticas relativas à configuração dos sistemas de saúde: o redimensionamento da atuação governamental, a divisão entre financiamento e provisão de serviços, a discussão acerca da abrangência do que deveria ser oferecido gratuitamente a todos, a seleção de intervenções baseadas em critérios de eficácia em termos de custo, os dispositivos de regulação da prestação de serviços médicos, enfim, temas mais ou menos polêmicos cuja discussão teve um significativo aporte do relatório de 1993, para o bem ou para o mal. É claro, com ele o Banco assumiu, senão a liderança, pelo menos um lugar de destaque no debate internacional acerca das políticas de saúde.

\section{A OMS e os sistemas de saúde}

Em meados de 1998, a dra Brundtland assumiu a direção da OMS. Seu currículo não deixa muitas dúvidas sobre suas qualificações para o cargo: ela ocupou por dez anos o cargo de primeira-ministra da Noruega, um dos países mais empenhados na ajuda externa. Nos anos oitenta, ela ganhou notoriedade internacional ao presidir a Comissão Mundial de Meio Ambiente e Desenvolvimento, que ficou conhecida como a Comissão Brundtland.

Logo em seu discurso de posse, ela deixava claro seus propósitos para a OMS: Eu vejo o papel da OMS como ser a voz moral e a liderança na melhoria da saúde das pessoas no mundo. Pronta e capaz de oferecer orientações nos temaschave que podem desatar o desenvolvimento e aliviar o sofrimento. Eu vejo nossos objetivos como sendo combater as doenças e a má-saúde - promovendo sistemas de saúde sustentáveis e equânimes em todos os países (Brundtland, 1998).

Esse discurso já deixava entrever que a OMS sob a nova direção empreenderia esforços no sentido de colocar mais ênfase no aconselhamento sobre as políticas de saúde que se referem à configuração dos sistemas de saúde.

De fato, na apresentação do Relatório da Saúde Mundial de 1999, Brundtland deixava clara a disposição de conduzir a OMS a uma posição no cenário internacional um pouco distinta da que ocupara ao longo das últimas 
décadas. Ela destacava que muitos governos buscavam em outras agências aconselhamento acerca dos assuntos que afetavam o setor como um todo, e advertia que a OMS precisava assumir um papel de suporte mais efetivo para os países, na medida em que os mesmos reformavam e reestruturavam seus sistemas de saúde (WHO, 1999).

Nesse sentido, a OMS se engajou num esforço de pesquisa, no intuito de construir indicadores do desempenho dos sistemas de saúde. O produto desse esforço, que contou com a colaboração de dois membros da equipe que elaborou anos antes o documento "Investindo em saúde" 7 , foi divulgado pela primeira vez no Relatório da Saúde Mundial de 2000 (WHO, 2000): uma escala do desempenho dos diversos sistemas nacionais de saúde dos países-membros. A divulgação provocou uma grande polêmica. Surgiram várias críticas ao processo de construção dos indicadores utilizados para construir a escala dos países.

Independentemente dessas críticas, cujo exame ultrapassa os objetivos deste artigo, o documento da OMS pretendeu trazer para o debate acerca das políticas algumas contribuições. De um lado, ele pretende oferecer uma ferramenta para medida do desempenho dos sistemas de saúde, que passaria a ser feita sistematicamente, com periodicidade anual. Seria criado, assim, um novo tipo de indicador resumo, análogo ao Índice de Desenvolvimento $\mathrm{Hu}$ mano desenvolvido pelo PNUD, só que voltado para os sistemas de saúde, e sob a égide da OMS.

De outro, o documento destaca duas dimensões até então deixadas de lado nas discussões acerca dos sistemas de saúde. Embora o objetivo principal de um sistema de saúde seja melhorar a saúde, o documento defende que o sistema deveria também corresponder às expectativas de seus usuários, e ser justo no que diz respeito à relação entre seus dispositivos de financiamento e as realizações concretas do sistema. Nesta última dimensão, o documento ressalta a importância de que um sistema de saúde proteja especialmente os mais pobres dos gastos volumosos que decorrem de seu súbito adoecimento. É nesse sentido que o documento defende a adoção de dispositivos de prépagamento.

É cedo para avaliar o impacto dessa iniciativa da OMS no debate das políticas de saúde no cenário internacional. Mas tudo indica que há um esforço da OMS em assumir um lugar mais proeminente no debate acerca das refor- mas e reestruturações dos sistemas de saúde na próxima década.

\section{Considerações finais}

Ao longo dos anos noventa, as agências internacionais enfatizaram a oferta de idéias sobre quais seriam as políticas mais adequadas para os países em desenvolvimento. O Banco Mundial conquistou lugar proeminente nessa oferta de idéias, ao lograr apresentar um conjunto de sugestões sobre as reformas dos sistemas de saúde e das próprias atribuições dos governos no setor. No final da década, contudo, assistimos a um esforço da OMS para assumir a liderança no que diz respeito ao aconselhamento junto aos governos sobre o andamento das reformas e reestruturações dos sistemas de saúde.

Há algo em comum nessas iniciativas de oferta de idéias por parte do Banco Mundial e da OMS: ambas buscam apresentar as recomendações sobre os sistemas de saúde e suas reformas como se as mesmas decorressem de um conhecimento universal, portanto, universalmente aplicável. Ambas envolvem um considerável esforço de pesquisa, conduzidos por técnicos altamente qualificados, mas que se faz um pouco à margem do debate político entre os representantes dos países-membros. Esforço de pesquisa que, ao fim e ao cabo, oferece critérios para distinguir, entre as diversas experiências de reforma em curso, aquelas que seriam mais adequadas. E, desse modo, permitem oferecer à comunidade de ajuda ao desenvolvimento, parâmetros para a alocação de recursos. Comunidade que, se aceita tais critérios, pode privilegiar, na alocação de seus recursos, os países que claramente aderem às lições propostas. Quer pela força das idéias supostamente universais, quer pelo constrangimento mais indireto, aliás, análogo ao aplicado por vários agentes econômicos privados que atuam nos mercados financeiros internacionais, este novo padrão de oferta de idéias parece seguir cumprindo um papel de disciplinar as políticas dos países em desenvolvimento.

Mas talvez as premissas que servem de ponto de partida da elaboração dessas propostas não sejam tão universais assim. E talvez sejam bastante distintas das premissas (crenças e valores) que consideramos válidas para nossa cultura, sobre os quais desejamos erigir nosso sistema de saúde. Para nós, brasileiros, que entendemos que a saúde é um direito universal e 
que o Estado tem o dever de assegurá-la, e que lutamos pela consolidação de um sistema de saúde que concretize esses princípios, todo o debate dos anos noventa pode parecer estranho. Contudo, a oferta de idéias das agências internacionais pode nos ser bastante úteis. Não tanto pelas lições e recomendações sugeridas, nem tampouco pelos critérios de hierarquização das experiências de reforma. Nessa pers-

\section{Notas}

1 O termo Nações Unidas foi utilizado pela primeira vez por sugestão do presidente norte-americano Franklin Roosevelt para designar o conjunto de nações que se uniam no esforço de enfrentar a ameaça da Alemanha e de seus aliados. Com o fim da guerra, o termo passou a designar o conjunto de organismos internacionais que assegurariam a paz e a segurança mundial. Como diz $\mathrm{Ar}$ righi, o aspecto crucial da visão de Roosevelt era que a segurança do mundo tinha que ser fundamentada no poder norte-americano, exercido através de sistemas internacionais. Sobre o tema, vide Arrighi, 1996.

2 A experiência de agências internacionais voltadas para a cooperação técnica na área da saúde é bem anterior ao nascimento da OMS. Foge por completo aos propósitos deste artigo examinar tais antecedentes, ou mesmo analisar a história específica da OMS, ou de qualquer das agências internacionais.

${ }^{3}$ Nem todos os países-membros podem tomar empréstimos da AID. Os critérios de elegibilidade (revistos anualmente) privilegiam países mais pobres e com menor capacidade de obter recursos financeiros diretamente nos mercados internacionais. Analogamente, nem todos os países-membros do BIRD podem obter empréstimos. O Brasil, por exemplo, pode tomar empréstimos do BIRD, mas não da AID.

4 A necessidade de proceder tal demarcação foi inicialmente posta pelo G-7, grupo que reúne os principais governos do mundo. Porém, talvez indo além das expectativas originais, ao longo da década as diferenças entre o FMI e o BM tornaram-se mais evidentes ao final da década.

${ }^{5} \mathrm{~A}$ tradução de todas as citações de originais em inglês foi feita pelo autor.

6 Só como exemplo, o Programa das Nações Unidas para o Desenvolvimento (PNUD) divulga anualmente o Relatório sobre o Desenvolvimento Humano; a OMS, o Relatório da Saúde Mundial; o Banco Mundial, o Relatório sobre o Desenvolvimento Mundial etc.

7 Os dois membros são C. Murray, que no início da década concebeu o sistema para medidas dos anos de vida ajustados pela incapacidade, e que atuou no desenvolvimento dos indicadores, e P. Musgrove, que se tornou o editor chefe do Relatório da OMS em 2000. pectiva, talvez o nosso esforço adicional de pesquisa deveria se dar no sentido de extrair desse debate as questões e desafios postos ao tipo de desenvolvimento de sistemas de saúde com que aspiramos. Desafios que temos que enfrentar e superar no processo de sua construção, mesmo que por caminhos distintos dos sugeridos pelas agências internacionais.

\section{Referências bibliográficas}

Arrighi G 1996. O longo século XX. Dinheiro, poder e as origens de nosso tempo. Contraponto, Rio de Janeiro.

Banco Mundial 1993. Relatório sobre o Desenvolvimento Mundial 1993: investindo em saúde. Fundação Getúlio Vargas, Rio de Janeiro.

Brundtland GH 1998. Acceptance speech for the World Health Assembly, 13 May 1998. Disponível em: $<$ www.who.int/director-general/biographies/gh_ brundtland.en.html $>$. Acessado em 1o de abril de 2001.

Fiori JL 1997. Globalização, hegemonia e império. In Tavares MC \& Fiori JL (org.). Poder e dinheiro: uma economia política da globalização. Vozes, Petrópolis, pp. 87-147.

Lancet, The 1993. World Bank's cure for donor fatigue. The Lancet, 342:63-64.

Mattos RA 2000. Desenvolvendo e ofertando idéias: um estudo sobre a elaboração de propostas de políticas de saúde no âmbito do Banco Mundial. Tese de doutorado em saúde coletiva, Instituto de Medicina Social UERJ, Rio de Janeiro, (mimeo).

OECD/DAC 1996. Shaping the $21^{\text {st }}$ century: the contribution of development co-operation. OECD, Paris.

Teixeira A 1994. O ajuste impossível: um estudo sobre a desestruturação da ordem econômica mundial e seu impacto sobre o Brasil. UFRJ, Rio de Janeiro.

Unicef 1996. Fifty years for children. In The state of the world's children. Disponível em www.unicef.org/sowc 96/50years.htm. Acessado em setembro de 1998.

Wade R 1996. Japan, the World Bank, and the art of paradigm maintenance: the East miracle in polítical perspective. New Left Review, 217: 3-36.

Walt G 1996. Health policy: an introduction to process and power. Zed Books, Londres.

Who 1999. The world health report: making diference. Geneva.

Who 2000. The world health report - health systems: improving ierformance. Geneva.

Wolfensohn JD 1997. O desafio da inclusão. Discurso apresentado à Assembléia dos Governadores em HongKong, no dia 23 de setembro de 1997. Disponível em <www.worldbank.org/html/extdr/am97/jwsp978.ht m>. Acessado em 10 de abril de 2001.

World Bank 1987. Financing health services in developing countries: an agenda for reform. World Bank (A World Bank Policy Study), Washington.

World Bank 1997. Health, nutrition \& population. World Bank (Sector strategy), Washington. 